\title{
Institutional Research in South African Higher Education: Framing the Contexts and Practices
}

\author{
Jan Botha, Nicole Muller, Karen Webber
}

\section{Research focused on universities as institutions in the broader context of research on higher education}

Universities are among the oldest social organisations in the world. Few would doubt that universities are crucially important social organisations. The public and private good of universities is generally recognised (and widely debated, cf. Singh 2001). The broad range of purposes ascribed to universities and society's expectations of the value added by universities add up to form an intriguing phenomenon which is the object of research in a range of academic disciplines and professional practices.

Castells (2001:206-2011) distinguishes four major functions of universities. Despite the ideology of a value-free role for universities, they function, firstly, as ideological apparatus, that is, as producers of values and social legitimation. They are responsible for the shaping of civic values and the development of "flexible personalities" and "prospective identities". In order to do this, universities "use future-orientated narratives to construct a new basis for social belonging and citizenship" (Cloete \& Maasen 2015:3). Secondly, universities play a key role in the selection of the dominant elite through the formation of networks and the establishment of the codes that distinguish between the elite and the rest of society. In recent decades, as a result of the massification of higher education, the notion of 'elite' has changed from the selection of students from a political and social elite class to an academic elite, those with the highest academic talents. Thirdly, universities are responsible for the higher levels of education and for the training of the labour force. In the earliest times, the role of universities was to train the clergy. This has developed to include the selection and preparation of those responsible for the state bureaucracy and the training of professionals (in medicine, law, engineering and other professions). More recently, universities have become institutions where students "learn to learn", therefore, the functions of universities are reaching beyond the reproduction and transmission of knowledge. Fourthly, in the most recent phase in its development, going back to the German research university and the American land-grant universities of the 19th century, universities are expected to produce scientific knowledge and to support society in the application of knowledge for the sake of socio-economic development and the general well-being of humanity and the environment.

It comes as no surprise, therefore, that such a venerable and important social institution would be the object of extensive and on-going research. Institutional research (IR) is a component of this research. IR has a specific focus: it is research aimed at the understanding 
of universities as institutions or, in the formulation of Calderon \& Webber, "the nature of IR work is that it is about the institution and for the institution" (2015:10).

IR as a focus area within the broader field of higher education research (HER) has developed over the past fifty years or so into an established field of scholarship and practice, based in institutions and organised into a network of professional and academic associations across the world (Reichard 2012:3-21). IR is usually understood as applied and actionable research aimed at decision-makers in Higher Education institutions and at policy-makers in regional and national Higher Education systems. The purpose of IR is primarily to inform institutional planning, policy development and decision making. The application, management and analysis of institutional information remains a key concern of IR practitioners, although, given the importance of information in our day and age ("information is the new oil"), the role of IR practitioners as the knowledge analysts of the post-secondary industry is expanding into many other roles, including that of high-level consultants to senior institutional managers and government officials.

\section{Intersecting contexts and practices: Institutional Research in South African Higher Education}

In this book, twenty-six authors from twelve universities in South Africa, as well as one in the USA, one in Australia, and one from the Department of Higher Education and Training in South Africa, present the results of research projects undertaken specifically for the purpose of this book, namely, to analyse, explain and reflect on the history of Institutional Research (IR) in South African Higher Education, its current state and possible future directions.

In this chapter, we provide the background and rationale for the book and give overviews of important concepts to serve as a generic framework for the specific themes of the different chapters. Firstly, we locate IR within the broader context of research on higher education and give a general definition of IR. We deliberately leave the definition at a generic level because a number of the chapters in the book discuss the variety of more specific definitions of IR which the authors have developed in their analyses and arguments. These more specific understandings of IR are informed and influenced by the context of higher education in South Africa. IR is influenced by and practised within a range of intersecting contexts. This is demonstrated by the range of themes covered in this book. Notwithstanding this variety of contexts, transformation is an important theme that is pervasive in South African higher education and it forms the background for much of the work of IR practitioners in this country. We therefore provide, secondly, an overview of the transformation of higher education during the democratic dispensation in South Africa (since 1994). In the third section of this chapter, we return to definitional matters and introduce a number of the leading theorists in the field of IR in higher education, in particular, the work of Terenzini and Volkwein. Since many of the authors of the chapters in the book base their analytical work on these theorists, it is necessary to provide an overview of the main tenets of these theories at the outset in order to provide a broad analytical and theoretical framework for the book as a whole. In the fourth and final section of this chapter, we provide an overview of the contents of the book. 
The intended readership of the book includes leaders in higher education institutions (executives, deans/directors, heads of departments, leading academics, and others); higher education professionals working at system level and higher education professionals working in institutions (including IR practitioners, quality assurance officers, research support officers, teaching and learning support staff, and staff working in finance, human resources and facilities management departments, etc.); researchers in higher education studies; postgraduate students in (higher) education studies; and executives and staff members of international foundations.

A notable characteristic of this book is that the authors represent a mix of practitioners based in IR units in universities or in a government department and scholars/academics based in academic departments and centres in universities. Throughout the book, a constant discussion point relates to institutional researchers as practitioners and/or as professionals and/or as scholars and academics. Kehm (2015:63-64), building on the work of Teichler (2000:19-21), distinguishes five types of higher education researchers: (a) discipline-based occasional researchers (for example, economists or political scientists, who would, on occasion, devote their work to themes in the field of higher education), (b) researchers in the academic discipline devoted to higher education (e.g. educationalists based in a university who focus their research on a continuous basis on higher education), (c) researchers (often externally funded) based in a research unit, (d) applied higher education researchers whose work is determined by its utility for (institutional) decision-making and who are often also responsible for data collection, management and interpretation, and (e) reflective practitioners (for example, executive and senior academic managers of universities or politicians or civil servants with a specific interest in higher education). Representatives of categories (b) and (d) are most prominent in this book. Moosa and Murray (Chapter 7) argue that both groups will benefit from more interaction and exposure to the other group's work. The work of the researchers with an academic interest (the first two of Teichler's and Kehm's categories) have more freedom to choose the themes they want to focus on, their work is usually more explicitly theoretically informed, they have more time to conduct their research, and it is established practice that they publish their work in scholarly books and journals. The applied researchers (the fourth type), on the other hand, are often working under pressure to provide at short notice for the immediate needs of their institutions. They therefore they have less freedom to choose their own themes for research, their work is often less explicitly theoretically informed and in most cases they do not publish their work in scholarly books and journals. As a consequence, most of their outputs end up as "grey literature" that is not publicly available (see Chapter 3).

One of the purposes of this book is to provide the opportunity for the applied researchers (in this case, the IR practitioners), to publish their work in a scholarly book to provide a window on this dimension of the spectrum of higher education research. While the applied researchers and IR practitioners are often seen as "back room workers", none of the other types of researchers would be able to do their own work were it not for the outputs of the IR practitioners, in particular, the data collected and provided by them. It is argued in various chapters, however, that IR practitioners are not simply data providers. They are what Whitchurch (2008:34) calls "third space" or "blended" professionals in higher education, namely, individuals appointed in a tenured position, who are integrated within institutional 
structures, who are dedicated to a mix of academic and professional work, who make a career in their area of expertise, who join established networks and professional groups or associations and who contribute to the development of practitioner knowledge. These dimensions of the location and work of IR practitioners are all explored in this book, with up to date information on the intersecting contexts and practices characterising IR in South African higher education institutions.

IR in South African higher education is deeply interwoven with the transformation of higher education at institutional and system levels. Although there is not a chapter in this book devoted exclusively to transformation, the pervasive influence of systemic changes on IR in South African higher education forms the background against which every chapter has to be understood. In order to make that background more explicit, the next part of this framing chapter is devoted to the story of the dramatic changes of South African higher education over the past two decades.

\section{Overview of the transformation of Higher Education in South Africa during the democratic dispensation}

South African Higher Education prior to democracy (pre-1994) was a fragmented, insular, elite and uneven system. During the past 21 years this system has transformed, albeit with challenges, into a coordinated unitary system with the intention of ameliorating the negative impact of the apartheid legacy. In 2015/16, student protests about colonial symbols on campuses and about student fees took place at almost all South African universities. This student activism is the most recent phase in the transformation of South African Higher Education. It highlights the clash of competing developmental goals, which includes, in particular, successfully increasing access to Higher Education, improving quality and advancing expansion, and dealing with burgeoning costs in the face of static and declining resources. For many, higher education has become a mechanism of social injustice and exclusion, rather than holding to the aspirations of social justice, democratic citizenship, and economic and social development. Universities are struggling to manage in an uncertain environment.

Since 1994 South African higher education has undergone unprecedented change, both in pace of change and the introduction and implementation of new frameworks, legislation and policies, all requiring changes in practices. Jonathan (2006:66) contends that these additional pressures resulted in tensions "during a period of adjustment" in a sector in which there was already "an over-rich mix of understandings, expectations and pressures". She states that these pressures were all the more demanding because the sector until then had been unaccustomed to change; it was in "an unusual degree of stasis which had kept the normal currents of change at bay" (2006:66).

During 2015, the association of South African universities (which has the vice-chancellors as its board members) changed its name from Higher Education South Africa (HESA) to Universities South Africa (USAf). In an earlier phase, it was known as the South African Vice-Chancellor's Association (SAUVCA). In a recent study of the 21 years higher education development since the advent of democracy, the Association distinguishes between two 
periods, namely 1994-2007 and 2008 to 2015 (Universities South Africa 2015). We contend that the events begun in 2015, marked by renewed student activism and protest action calling for transformation of the sector, inaugurated the third phase in this ongoing process.

The first phase (1994-2007) was marked by the establishment of the new higher education environment. It focused on planning, governance and the funding of the system to try to rectify past inequalities and, in particular, to deracialising the policy environment inherited form the previous dispensation (Universities South Africa 2015:6). The second phase is characterised by the focus on institutional issues such as effectiveness and efficiency, institutional culture, language policies, student access with successful study completion, staff and student diversification, social cohesion, and state-sector relationships, amongst others (2015:6). Despite significant moves to change the size and shape of this sector, the South African higher education system remains an inverted pyramid, where universities dominate the size, shape, funding and support of the sector. This means that the largest participation rate occurs in the universities and universities of technology, which are the most expensive part of the system (Bawa 2011). The Technical and Vocational Education and Training (TVET) colleges comprise approximately one-quarter of the system and receive considerably less government funding and support. This inversion is exacerbated by poor articulation between and across the levels of the pyramid. Universities South Africa (2015) recognises that rectifying this inverted pyramid is a necessary transformation requirement that requires re-mapping the Higher Education landscape to ensure a more appropriately organised and resourced sector.

Twenty-one years into the democratic era, South African higher education was brought into the global spotlight by the 2015 student activism and protests around the perceived lack of transformation in some areas, and the slow speed of change in others. Students do not see the gains of the democratic dispensation translated into material transformation. New terminology has emerged amid the proliferation of social media hashtag campaigns such as \#RhodesMustFall, \#FeesMustFall. Amongst many other issues, the student protests speak to themes such as the "decolonisation of universities and of the curriculum", and to the need for universities to be "safe spaces". These student protests highlight numerous inequalities and examples of the lack of transformation, with the complaint that universities are not fully cognisant of, nor responding to, "the realities of highly segmented, socially diverse and cognitively differentiated learning communities" (Universities South Africa 2015:10). These 2015/16 student protests have been described as "the largest and most effective student campaign in post-1994 South Africa" (Badat 2016).

The complexity of transformation in South African higher education institutions, and particularly of the former white universities, is strongly portrayed by Tabensky and Matthews (2015) in their book, Being at home: race, institutional culture and transformation at South African Higher Education Institutions. They emphasise that many of the contested issues are also relevant in other countries in the world where institutions are faced with the challenge of transforming their institutional cultures and looking for ways to be more welcoming and accommodating to students who have previously been sidelined or excluded (2015:2).

For the purposes of this brief overview, three significant documents and events are mentioned that lay the foundation for changes and shifts in South African higher education. Firstly, the 
South African Constitution commits the state and all the institutions of the nation to the assertion of the values of human dignity, the achievement of equality, the advancement of non-sexism and non-racialism, to uphold the human rights and freedoms that the Bill of Rights proclaims, and to "respect, protect, promote and fulfil the rights" embodied in the Bill of Rights (RSA 1996). Secondly, the Education White Paper 3 of 1997, with the title $A$ programme for the transformation of Higher Education, is recognised as the cornerstone of the transformation policies in higher education. It identifies various social purposes that higher education is intended to serve, including to contribute "to the social...cultural and intellectual life of a rapidly changing society", to socialise "enlightened, responsible and constructively critical citizens" and to "help lay the foundations of a critical civil society, with a culture of public debate and tolerance" (RSA 1997a:3, articles 1.12, 1.3, 1.4). Thirdly, the Higher Education Act of 1997 declares the desirability of creating "a single co-ordinated higher education system", restructuring and transforming "programmes and institutions to respond better to the human resource, economic and development needs" of South Africa, redressing "past discrimination", ensuring "representative and equal access" and contributing "to the advancement of all forms of knowledge and scholarship, in keeping with international standards of academic quality". The Act also proclaimed that it was "desirable for higher education institutions to enjoy freedom and autonomy in their relationship with the State within the context of public accountability and the national need for advanced skills and scientific knowledge" (RSA 1997b).

Building on these foundational documents, a number of subsequent policy and planning documents were developed and the implementation of these policies play a key role in the transformation of higher education: the National Plan for Higher Education (RSA 2001); the Report of the Ministerial Committee on Transformation and Social Cohesion and the Elimination of Discrimination in Public Higher Education Institutions (Department of Education 2008); the Declaration of the Higher Education Summit on Transformation (2010); the White Paper for Post-School Education and Training (RSA 2014) which seeks to provide a far more articulated and integrated post-school environment. The National Development Plan (RSA 2012), an aspirational document, sets targets for equity and development in society in general and specific targets for higher education.

In South Africa's history, transformation is largely, but not solely, referenced around race. Transformation in higher education was often seen as the change in the composition of student bodies to include greater participation by formerly disadvantaged and marginalised students. It is not, however, advisable to take such a reductionist view of transformation. In their briefing paper on transformation, USAf identifies a number of critical areas where transformation is required.

Firstly, there is the lack of transformation in the cultures of governance and leadership, where these have "simply morphed into the new era, with its essential features, symbols and practices left more or less unbroken" (USAf 2015:7).

Secondly, USAf points out the "lack of growth, low participation, high attrition, low completion and variable quality" (2015:10) relating to equity of access and success. This is undoubtedly a challenging and multi-faceted dimension as it engages with every aspect of student life at the university, including the following: inadequate student financial support, the high student 
to lecturer ratios at many institutions which are unacceptable and unsustainable, the uneven distribution of high-quality teaching and learning infrastructure, the fact that the curricula are "designed for highly-compressed learning experiences favouring a smaller segment of the student population, not accommodating multiple temporal track, and not making sufficient provision for differentiated forms of teaching and learning support"(2015:10), and the disproportionate focus on the importance of research as against the perceived status of learning, and learning as scholarship and praxis (2015:10).

Thirdly, USAf points out that the challenges related to staffing at universities are perhaps "the most glaring collective failure of the sector to date" (2015:11). While student enrolment has seen a significant change in participation by former marginalised groups, the profile of staff, and of academics in particular, remains largely unchanged, particularly at historically white institutions. Aligned with the lack of demographic change is the urgent need to address the "intellectual and academic capabilities related to teaching and learning, research and community engagement that are fundamental to the transformative role of our universities" (2015:12).

Fourthly, USAf points out that the cultural and social environments (institutional culture) of universities have not transformed sufficiently. This was made very clear by the students in their 2015 protest actions. The student hashtag campaigns "generated fierce debates on the role of 'culture' in the intellectual assumptions on which most universities in South Africa have been founded, including the dominance of Eurocentric epistemology, pedagogy and curricula, and its silences, if not hostility to knowledge, culture, ideas and traditions from and about African realities, and more specifically, black experiences" (2015:12-13).

In the fifth place USAf emphasises that institutional equity and transformation are dimensions of higher education that relate, on the one hand, to the challenges faced by some institutions from being chronically underfunded for years, and, on the other hand, the Government's inability to move these institutions towards more sustainable operations (2015:19). This relates closely to the need to transform funding for higher education, with the question whether transformation can occur on ever declining levels of state funding to universities. Of course, there are many other aspects of transformation that are specifically espoused in the Constitution, including sexism, class discrimination, homophobia, and xenophobia (Tabensky and Matthews 2015:3).

So what are the implications of this all for IR practitioners in higher education? What is the impact on the nature and purposes of IR in South Africa of this uncertainty and complexity and of cries for faster and deeper transformation? We recognise that in some measure, this book, notably in the profile and demographics of its authors, reflects the degree to which transformation is yet to occur this field of practice. Another important consideration that has not emerged in this book, is how progress in transformation can be measured. If, as Universities South Africa contend, we need to recognise the "multi-dimensionality, interconnectivity and relational nature of that which we seek to transform" then "[t]he precise ways in which specific institutional cultures 'construct' these relations is a matter of further empirical investigation" (USAf 2015:22). 
This links well to Terenzini's three levels of organisational intelligence $(1993,2013)$ with the role that Institutional Research can play in understanding the university within context, culture and environment. Specific definitions and understandings of understanding the 'state of transformation' need to be developed: "Hopefully, a more complex system revealing uneven, contradictory and convergent processes of change and resistance to change will emerge, so that we can appreciate the full 'balance sheet' of social transformation in higher education" (USAf 2015:22). Universities South Africa is already embarking on a process to develop a set of indicators which can be adapted to the relevant contexts of institutions. This provides an important opportunity for IR in South Africa.

\section{Definitions of, and theoretical perspectives on, institutional research}

Engaging with and building on the work of leading IR theorists, the authors of this book tell the story of IR in South African Higher Education and highlight the range of intersecting contexts and practices characterising this field of scholarship and practice in this part of the world. Among the theories that inform the chapters in this book are Terenzini's notion that IR should ideally consist of three tiers of institutional intelligence (technical/analytical intelligence, issues intelligence and contextual intelligence), that there is a synergy between the tasks that comprise IR's "Golden Triangle" (Volkwein 1999), and that IR practitioners perform a variety of roles that must be acknowledged and balanced (Volkwein's "Four Faces of $\left.I R^{\prime \prime}\right)$. Since many of the chapters in this book are based on the theoretical insights of Terenzini and Volkwein, we provide a summary of their work here. In the chapters in this book, many of the authors discuss those aspects of the work of these and other theorists that are of particular relevance to their analysis and argument. It is therefore deliberate that there are some overlaps and repetition of material in the different chapters. We wanted each contribution in the book to make sense in itself and as a constituent part of the larger context of the book.

While IR is a known function in higher education around the world, it has been in existence in some parts of the world for a longer time, and is thus more deeply entrenched there. Many of the roles and responsibilities practiced today are based on the definition and details provided by early leaders in the USA that include Joe Saupe and Cameron Fincher. Saupe $(1981$; 1990) reminds us that IR is "primarily that research that is conducted within an institution that supports institutional planning, policy formation and decision making" (1990:1). With a focus on a specific institution or system of higher education institutions, IR activities most often use data and analyses that assist in short and long term planning. It is research that is objective, systematic, and thorough. Fincher $(1978 ; 1985)$ described IR as a specialised administrative function and fittingly styled its practitioners as organisational intelligence specialists. For Fincher, IR offices are seen as the 'engine room' of the university; developers of policy-related research and research-led policy, and catalysts for institutional change.

A number of noted scholars have discussed the roles and responsibilities of IR (e.g. Maasen \& Sharma 1985, Peterson 1999 Volkwein 1999, Delaney 2009, Leimer \& Terkla 2009, Reichard 2012; Huisman 2013; and Teichler 2013). As we note in the concluding comments at the end of this book, there are a number of differences and tensions that 
affect the application of IR in different environments (including local or national policies). Fundamentally, IR practitioners, armed with the general knowledge of a broad understanding of higher education trends and the uniqueness of the specific context, are charged with the collection, analysis, and effective reporting of data that provides a better understanding of the institution and information to support effective strategic planning.

The field of IR has now reached a level of maturity that can be seen in the number of higher educational staff members that perform roles related to IR responsibilities and from the accumulated volume of published works available. Some USA institutions, including the University of Georgia, University of California Berkeley, and the University of Michigan who pioneered the IR function, have dedicated staff and administrative offices to assist in institutional decision making. Professional associations for IR have also grown. Along with the upcoming celebration of 25 years of the Southern African Association (SAAIR), European AIR (EAIR) is nearing a 30-year history, and the Association for Institutional Research (AIR), based in the US, recently celebrated its 50th anniversary. Many individual writings provide readers with information on a variety of issues related to IR, along with the New Directions for Institutional Research series (Jossey Bass/Wiley), and other publications available through the AIR. Two books that provide further evidence of the profession's level of maturity are The Handbook of Institutional Research edited by Howard, McLaughlin, and Knight (2012) and Webber and Calderon's (2015) Institutional Research and Planning in Higher Education: Global Themes and Contexts. Many of these publications are guided by theoretical concepts developed by scholars in the field of higher education research. In the latter book, Taylor (2015) describes the models of maturity that can be used to describe the evolution of institutional research that might help us think about the future of this field of work.

\section{Terenzini's "three tiers of intelligence"}

Along with a growing number of informative discussions on the form and function of IR, many practitioners have found value and guidance from a particular framework that outlines the practices and increasing sophistications that underpin effective IR practice. Terenzini's $(1993,2013)$ three tiers of institutional intelligence provide a structure for those who wish to further their effectiveness and breadth as IR professionals. Although individuals most often enter an IR position with some initials skills, Terenzini purports that, through experience and increased understanding, IR professionals increase their knowledge and skills and move to a subsequent (higher) level of intelligence. Institutional researchers who reach the highest tier of Terenzini's framework exhibit broad and deep skills, and are most likely to have the greatest impact on institutional change, thus providing greater value of IR to senior leaders and organisational management.

As the foundational building block, the technical/ analytical tier includes two types of intelligence: 1) technical knowledge of basic higher education definitions and categories, and 2) analytical knowledge of social science research. The acquisition of basic definitions and categories provides the Tier 1 practitioner with an understanding of higher education role players and structures, such as who a student is (e.g. full-time, part-time, traditional, distance-learner), how staff members are categorised, and what the difference between student headcounts and full-time equivalents (FTEs) is. Analytic knowledge includes a basic 
understanding of how to measure, collect, and analyse data, along with principles of research design, statistical methods, and use of statistical software. While many of these research and technical skills are often learned in one's graduate programme, some of the knowledge can be acquired or further enhanced through on-the-job training. In particular, definitions and systems that are unique to an institution must be learned on the job (Terenzini 2013).

Once IR practitioners have gained a solid understanding of the institution's organisational structure, leadership, and organisational practices, they may be engaging in Tier 2 intelligence, called "issues intelligence". At this level, the researcher is aware of issues that affect senior leader decisions, and constraints that may contribute to those decisions. Practitioners using Tier 2 intelligence are aware of organisational structures, cognisant of the relationship of the institution to external stakeholders, and understand the institution's goals and strategic plans (Terenzini 2013). Tier 2, similar to Tier 1, is learned through a mixture of on-the-job training and formal coursework.

The practitioner who performs at the third tier, contextual intelligence, is able to synthesise a deep knowledge of higher education in general and of a particular institution. At this level, the Institutional Researcher knows the specific history, function, and structure of a specific university very well. The researcher must also know about higher education on a broader scope. He or she understands how the university fits into the local, national, and international system of higher education. Uniquely, in contrast to the previous two tiers, contextual intelligence can be gained only through on-the-job training (Terenzini 2013).

As the 'Queen Tier,' level 3 intelligence is the pinnacle of the pyramid, but it depends on the other two tiers for support. The contextually-intelligent IR professional not only commands the analytical and personal skill sets and understands the topical domains that comprise Tiers 1 and 2, but also understands how to blend those two intelligence sets in a detailed and nuanced grasp of the context and culture of a particular IR operation - the institution where IR professionals practice their craft (Terenzini 2013).

Our interpretation of Terenzini's conceptualisation of organisational intelligence indicates that IR professionals should strive to move from Tier 1 to Tier 3, but new technology and new organisational processes require the professional to engage in tasks in the first two tiers as well. Therefore, our interpretation of optimal organisational intelligence motivates the IR practitioner to cycle between the tiers or perhaps to be engaged in some tasks at multiple levels.

Although time spent on tasks in each tier is important, IR offices with a small staff may lack personnel and the breadth of reporting obligations to find time for the work that contributes to the contextual intelligence tier. This dilemma may, however, be a very good reason why IR officials should strive to develop office procedures that efficiently address the needed tasks that utilise Tier 1 skills, so that attention can be focused on developing skills that are situated in the third level. 


\section{Volkwein's "Golden Triangle"}

As the field of institutional research has grown, so has the professional identity that is associated with IR and decision support. As the field expanded, it has acquired a set of job titles (with some variety, but many similarities) and some common nomenclatures. In addition, the profession identifies its members by their similar postsecondary training and knowledge of higher education.

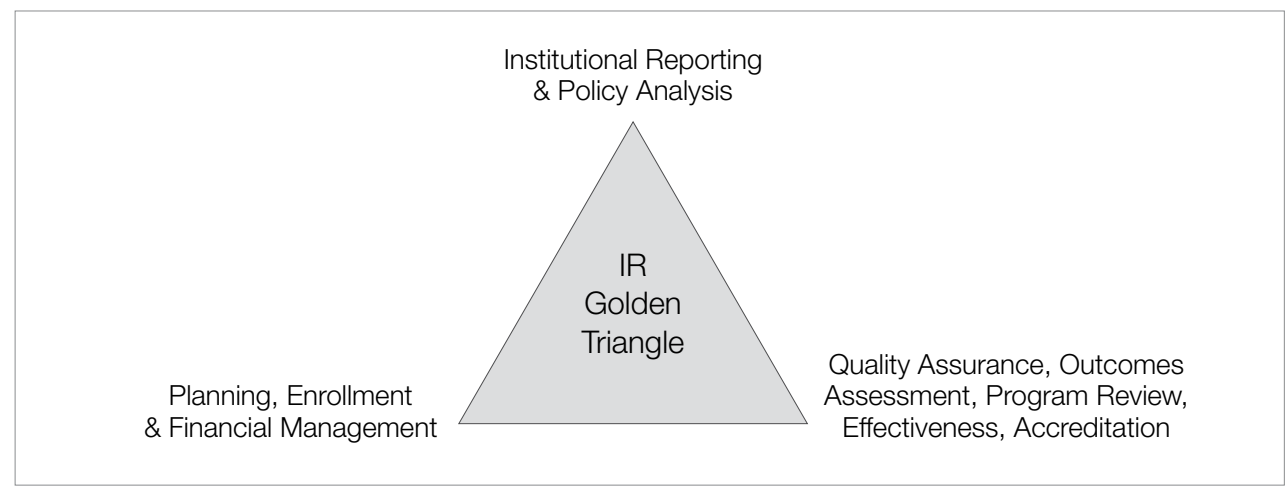

Figure 1: The Golden Triangle of Institutional Research Analysis

(Source: Adapted from Volkwein 2008)

Practitioners may be identified by a variety of terms and perform their tasks with differing priority (e.g. institutional research, planning, assessment, institutional effectiveness, and decision support). Regardless of the specific name, Volkwein (2008; Volkwein, Liu, \& Woodell 2012) reports that at most institutions there are strong connections, if not formal organisational arrangements, between the people who perform analytic functions in 1) institutional research and analysis; 2) planning and budgeting; and 3) assessment, accreditation, and effectiveness. Volkwein graphically represents this relationship through the Golden Triangle of Institutional Research. Volkwein et al. (2012) purport that tasks assigned to individuals in these three areas predominate most of the practice of IR.

As the IR practitioner endeavours to fulfil his/her duties, a variety of campus dualities, tensions and even institutional policies vie for focused attention. In addressing the decision support needs of the campus, IR practitioners are required to assume several different roles, in part, based on the task at hand. To address the differing roles that IR practitioners must play, Volkwein (1999) identified four types of roles that he calls the Four Faces of IR: IR as information authority, IR as policy analyst, IR as spin doctor, IR as scholar/researcher. A decade later, Serban and Luan added a fifth face, IR as knowledge manager (see Table 1).

As shown below, the typology distinguishes between IR purposes and audiences that are more formatively, internally, and improvement oriented, and those that are more summative and accountability oriented. The vertical axis describes the organisational roles and cultures. Combining these categories thus produces a typology of four overlapping but distinct types of IR purposes and roles. When serving as the Information Authority, the IR practitioner is 
providing the core information about the institution - its shape and size, students and staff, and various organisational activities. As the Policy Analyst, the IR practitioner works with senior administrators as an analyst or consultant, providing analytic support for planning and budget decisions, policy revisions or other needed change. In this role, Volkwein says that the analyst is providing valued information that is educating the management team. Often, IR practitioners must provide information for information or reports that require the analyst to serve in an advocate role, summarising information that reflects the institution's position for external reviews such as accreditation. Volkwein terms this role as IR as Spin Doctor, and notes that as an important role for the IR professional, it is important to maintain ethical behaviour that can present the best case for institution. Lastly, there are times when the IR analyst will be called upon to serve as the impartial researcher and scholar who investigates and produces evidence of institutional effectiveness. As the knowledgeable IR Scholar and Researcher, one has the opportunity to support IR and the institution through this role.

\section{Table 1: Five faces of institutional research}

\begin{tabular}{|c|c|c|}
\hline \multirow{2}{*}{$\begin{array}{l}\text { Organisational Role and } \\
\text { Culture }\end{array}$} & \multicolumn{2}{|c|}{ Purposes and Audiences } \\
\hline & $\begin{array}{l}\text { Formative and Internal, for } \\
\text { Improvement }\end{array}$ & $\begin{array}{l}\text { Summative and External, for } \\
\text { Accountability }\end{array}$ \\
\hline $\begin{array}{l}\text { Administrative and } \\
\text { Institutional }\end{array}$ & $\begin{array}{l}\text { To describe the institution; } \\
\text { IR as an information authority }\end{array}$ & $\begin{array}{l}\text { To present the best case; } \\
\text { IR as spin doctor }\end{array}$ \\
\hline $\begin{array}{l}\text { Academic and } \\
\text { Professional }\end{array}$ & $\begin{array}{l}\text { To analyse alternatives; } \\
\text { IR as policy analyst }\end{array}$ & $\begin{array}{l}\text { To supply impartial evidence of } \\
\text { effectiveness; } \\
\text { IR as scholar and researcher }\end{array}$ \\
\hline Technology & \multicolumn{2}{|c|}{$\begin{array}{l}\text { To gather and transform data into information and knowledge; } \\
\text { to collaborate in creating and maintaining information repositories and to facilitate the } \\
\text { process of knowledge cretaion, capture and sharing; } \\
\text { IR as knowledge manager }\end{array}$} \\
\hline
\end{tabular}

(Source: Serban 2002)

Clearly, some IR activities overlap across these four roles and are difficult to classify. A fact book, for example, has both internal and external audiences, and mandated external reports may have both descriptive and analytical dimensions. Studies on student enrolment or faculty workload may fit in any of the four quadrants, depending on the audience of the report and how the report is developed. We agree with Volkwein (2008:20) that the boundaries of these four faces of IR may blur across certain situations, and that prompts the need for astute IR practitioners to be well versed in all so they can play all four roles effectively.

\section{Overview of the contents of the book}

This book contains four sections, namely Section A: History and development of IR in South Africa; Section B: IR and higher education steering instruments; Section C: IR aimed at selfinsight and improvement; and Section D: Future directions for IR in South Africa. 


\section{SECTION ONE}

This section is devoted to the history and present state of IR in South Africa, informed by an analysis of the history of the SAAIR but also going beyond the activities of this Association. As is the case with volunteer associations in general, the development of the capacity and skills of its members has been an important focus of the SAAIR.

By means of an overview of the history of the Southern African Association for Institutional Research (SAAIR), established in 1994, Chetty, Bleazard, Naicker and Visser illustrate how the field of IR has developed in this part of the world (Chapter 2). The Association was established at a time when IR was in a fledgling phase of development, or not yet considered, in most South African higher education institutions. Influenced in particular by the work of the Association for Institutional Research (AIR) in the USA, a number of South African IR practitioners established an association that could coordinate efforts to enhance IR and to provide a networking opportunity for practitioners. The authors argue that three drivers have accompanied the development of IR in South Africa, firstly the different forms of government steering of higher education since 1994 (planning, funding and quality assurance), secondly the inspiration found in international examples as exemplified by the AIR and the European Association for Institutional Research (EAIR), and thirdly the technological advances that have drastically changed the manner in which data is gathered, managed, analysed, and used. Although the SAAIR has remained a fairly small and specialised organisation, it has maintained a high level of activity throughout its history and it compares favourably with similar international associations.

Expanding on the point of departure that the activities of the SAAIR serve as a lens through which the practice of IR in South Africa in a broader sense can be explored, Botha analyses the conference proceedings of the SAAIR from 1994 to 2015 and illustrates the synergy between IR and four significant periods of national policy development (Chapter 3). He determines that the SAAIR conferences are a good reflection of the interests and priorities of IR practitioners, in particular because IR practitioners have the freedom in the context of their voluntary association to set their own agenda. He illustrates that there has been, nonetheless, a synergy between the SAAIR conference events during 1994-2015 and the major policy developments in South African higher education. While a substantial number of conference events were devoted to the theme of "data management and the provision of information for the purposes of institutional decision-making and external reporting" and the theme of "IR best practices" (themes to be expected from a practitioner association such as the SAAIR), it is noteworthy that their interest in the theme of "data analysis in support of the enhancement of teaching and learning" - an important national policy priority - has increased over time. Furthermore, IR practitioners have maintained a significant interest in provision of data for the purposes of quality assurance, another priority in the national policy environment during the period under investigation.

Moving beyond the activities of the SAAIR, Muller, Langa and Dlamini (Chapter 4) give a snapshot of the present state of IR in a representative selection of higher education institutions in South Africa. They provide information on the qualification levels and years of experience of IR staff members, the functions for which IR units are responsible, the institutional locations and reporting lines of IR units within universities, and the competencies of the 
current IR staff complement in higher education. It transpires, firstly, that the focus in South African IR offices is still largely internally directed to the creation of intelligence for formative purposes, secondly, that South African IR efforts are still largely in the reporting domain and that their outputs are located in the technical/analytical organisational intelligence level, and, thirdly, that about half the respondents $(\sim 53 \%)$ identified a skills deficit in their IR offices and reported a serious need for the enhancement of their current skills. They argue that the practice of institutional research in South Africa will have to shift beyond the first level of organisational intelligence, and from the inward looking face of IR to a more proactive and influential role. IR practitioners in South Africa will have to embrace and understand the contextual intelligence challenges, in particular the challenges related to the next phases in the transformation of institutions and the higher education system, to support their institutions optimally.

The continuous development and future health of the practice of IR, and, possibly, its development into a fully-fledged profession, is the concern of the contribution of Visser and Barnes (Chapter 5). Expanding on the need for capacity and skills development for IR practitioners and also using Terenzini's framework of three types of institutional intelligence, Visser and Barnes report the results of their study of the professional development opportunities provided by the SAAIR since 1994. These activities focused on data management and reporting in terms of the Higher Education Management Information System (HEMIS), on the skills required by the quality assurance activities as institutional and national levels, and on the methodology and practice of IR. They argue that the changes in the technical environment, such as business intelligence, big data and learning analytics, will have an impact on all three tiers of organisational intelligence and that new knowledge and skillsets will be required by IR practitioners in future. The 'new' institutional researcher must have skills to find or direct others to meaningful (big) data and to make relevant connections. Programming skills combined with multi-source data mining, statistical modelling and prediction are now required. From an institutional and pedagogical perspective, it will be critically important that IR practitioners not only have the technical understanding of the new information environment, but also a thorough understanding of the factors that drive student learning and success as well as institutional success in a broader sense. Researchers and analysts will need to think very differently about the sourcing, extraction, manipulation and analysis of data. The key roles of institutional researchers will all be affected by (big) data. While pockets of capacity in some of these areas already exist among IR units in South Africa, these will have to be shared and expanded to ensure that institutional researchers keep up with these developments as they unfold in the near future and beyond.

\section{SECTION TWO}

The second section of the book is devoted to the three instruments used by the South African Government since 1994 to steer the higher education sector and its constituent institutions towards the achievement of the national goals for higher education. These instruments are planning, funding and quality assurance. As a sequence to the two chapters on planning (6 and 7) and one on quality assurance (8), two chapters on the measurement and monitoring of institutional performance (9) and on external reporting (10), complete this section. 
Planning as a steering instrument, and in particular the role of IR in support of planning, is considered from the perspectives of strategic planning and academic planning.

Nel (Chapter 6) assesses the role of IR in supporting strategic planning, organisational learning and renewal within a context of complexity. She argues that it is the responsibility of IR to transform data into knowledge that facilitates organisational learning with reference to three basic questions that strategic planning processes seek to address, namely, (a) Where we are now and where are we going? (b) Where do we want to go or where could we be going? and (c) How do we get there? Strategic planners require information from IR practitioners on the institution's current and past performance and capabilities (based on an analysis of both the internal and external environments), on its place within the educational landscape and on the resources and capabilities that the institution needs to achieve its desired strategic positioning and outcomes. Globally, higher education institutions are being called upon to navigate increasingly complex and uncertain terrains. In a situation of complexity, three principles of planning are relevant: firstly, to move from static to dynamic and iterative planning where plans are regarded as hypotheses about future developments; secondly, a transition from prescriptive to flexible planning modes; and thirdly, working with a hierarchy of plans which stimulates the self-organisational capacities of each level and improves ownership. In such a context the role of IR practitioners to support emergent and creative modes of planning becomes important. Nel illustrates how these roles of IR have played out in the strategic planning processes of a South African higher education institution that is the product of a merger between three higher education institutions.

Focusing on how academic planning strategy is affected by the government's steering mechanisms, and how such steering influences the planning of academic programmes, Moosa and Murray (Chapter 7) argue that institutional researchers have to shift from generating data for the purposes of reporting to using such data for academic programme planning and decision-making processes. They explain how the Government's steering of academic programmes is implemented through the programme criteria set by various national authorities. They conducted a survey to determine the support that institutional researchers provide to academic planners and found that in the decade since the implementation of the $\mathrm{CHE} / \mathrm{HEQC}$ programme accreditation system in 2004 such support to programme planning activities has been enhanced. This includes research by IR offices on national skills gaps, costing and budgeting for course/module design, course/module fee analyses, benchmarking for programme approval and reviews, progress towards meeting institutional academic goals, student evaluations of modules, support for teaching and learning, assessments of internal satisfaction, as well as a range of other surveys. However, impact studies, market research, graduate tracking and graduate destination surveys are areas where support for academic programme planning could be improved. An important finding of Moosa and Murray is that institutional researchers reported that they rarely consult scholarly higher education publications as sources of information for IR. They argue that the use of scholarly research can play a role to shift the work of IR practitioners from a reporting focus to scholarly outputs that can be of great value for academic programme planning.

Quality assurance (QA) as a steering instrument has been in sharp focus in South African higher education in the past two decades, and all indications are that this will continue to 
be the case, albeit with a shift in emphasis from quality assurance to quality enhancement. In South Africa QA has always been closely linked with IR (see Botha's thematic analysis in Chapter 3). However, questions remain whether this link is consistently manifested at the ideal levels within institutions or whether cooperation happens mostly on an ad hoc basis when a particular need arises. In Chapter 8 Geyser and Murdoch explore the maturity level and integration of QA and IR activities in public higher education institutions in South Africa. As indicators of cooperation and integration, they consider the naming conventions of QA units in 15 of the South African public universities, the functions allocated to QA units, the types of information required from QA units, and the maturity levels of the QA units. They apply theoretical frameworks developed for IR to the work of QA units, using Terenzini's framework of three levels of organisational intelligence to analyse the types of information provided by QA offices. They also employ Taylor, Hanlon and Yorke's maturity model to analyse the maturity of QA units. They found that the majority of the QA units seem to be independent and that they have specific functions that differ from the IR units. Geyser and Murdoch argue that both IR and QA inform decision-making, but that their contributions and their approaches to data collection differ and that the kinds of data/intelligence which they produce also differ. QA and IR staff play complementary roles and both make valuable contributions to insight into institutional realities.

One of the results of the enhanced planning activities in higher education was the significant expansion of reporting requirements. What good is planning after all, if the plans are not implemented and monitored? In Chapter 9 Bleazard shows how the global shift towards performance-related reporting in higher education since the 1980's has played out in South Africa and he illustrates how it affects the work of IR offices. In its most recent, and most intrusive form, performance-related reporting to the Government has taken on the form of reporting institutional performance to the Auditor-General on pre-determined objectives published in each institution's Annual Performance Plan and in a prescribed format. One may consider this development a logical outcome of the implementation of planning as a key government steering instrument. After all, planning calls for reporting if the loop is to be closed. Bleazard locates the new set of performance-reporting obligations within the existing reporting instruments and practices that have been developed by institutions over time and, based on a web-site review as well as a survey of IR offices across the country, he illustrates how IR offices are responding in innovative ways not only to these requirements but also how they continue to provide a wide spectrum of performance-related information tailored for different audiences. The IR offices of many of the universities surveyed are producing management information (or business intelligence) reports relating to institutional performance. Little of this is, however, being shared with the general public via their websites, except where published annual reports include a performance assessment. Bleazard maintains this situation can be expected to change when more South African universities begin to publish their annual reports on their public websites, given that their annual reports must now include a "performance assessment" section.

Visser and Skene (Chapter 10) take as point of departure for their contribution the observation that globally, including the Southern Africa region, mandatory and voluntary reporting to external bodies and agencies has increased in volume, quantity and complexity. This reporting is usually the primary reason why IR units are established. In small or 
understaffed IR offices it is often all that they do. The authors exlain how different models of the relationship between government and higher education institutions impact on the external reporting for which IR units are responsible. They distinguish between three such models, namely state control, state supervision and state inteference. While the nature and scope of external reporting differs between the three models, efficient and accurate external reporting processes remain pivotal to all successful submissions to the different regulatory bodies. The authors provide a comprehensive overview of the legislation currently governing the external reporting requirements of a number of countries in the southern African region (South Africa, Namibia, Botswana, Zambia and Zimbabwe) as well as the reporting requirements of international bodies such as UNESCO and the OECD. In addition to the mandatory reporting to the authorities, several South African higher education institutions provide institutional information on a voluntary basis to international ranking organisations. This form of reporting poses many challenges and creates extra work for IR practitioners because the definitions used by these organistions differ from the standard definitions used at country level. There is also, at a deeper level, an ongoing controversy about the appropriateness of the criteria for universities in developing countries. While many voices (including those in this book) advocate a changing IR role from merely reporting to many other roles, it is critical for IR units to retain a focus on reporting, particularly in the context of increasing calls for accountability and transparency.

\section{SECTION THREE}

The question of higher education outcomes and accountability is perhaps one of the most urgent and difficult issues that is of particular concern for government, higher education institutions and the general public. The importance of institutional self-insight and improvement specifically regarding teaching and learning, research and community engagement forms the basis of the third section of the book. The teaching-learning domain is explored through the lenses of data, teaching excellence and the student experience.

Fourie-Malherbe (Chapter 11) explores the role of IR to provide evidence of excellence in teaching and learning with reference to the teaching development grants provided by the South African government, and their impact on institutional strategies for teaching and learning. She conducted a case study of how a national development intervention to improve teaching is linked to institutional strategies in a particular institution. The Teaching Development Grant is a national intervention to improve student experience and success. She reflects on various considerations for the provision of evidence of teaching excellence and enhancement. These include adaptability in the face of changing conditions, working with resource constraints, availability of teaching and learning strategies and creating institutional cultures supportive of teaching excellence. Drawing on Biggs' (2001) quality model for teaching, she argues that IR is traditionally good at collecting, aggregating and interpreting data for levels 1 (student input) and 3 (student outcomes) but that there is little focus on the 'black box' of level 2, namely, the process level, or "what the teacher does". She concludes that there is a significant role for IR to play in coordinating data with teaching and learning initiatives to understand the 'black box'. She maintains that IR practitioners could play a greater role in providing information on excellence in teaching for informed decision making, and for effective strategies to enhance teaching excellence, and provides a number of suggestions as to how such agency could be achieved. 
While Fourie-Malherbe focused on a national intervention to improve teaching excellence, Lemmens and Henn, in Chapter 12, focus on the role of learning analytics (LA) to improve student learning outcomes. This specialised area in IR is rapidly gaining prominence in South African higher education institutions. LA is a critical entry point into student data to gain better insight into the student learning experience. It has emerged as a specific focus area in IR, alongside Academic Analytics. LA in South Africa is in its infancy. Lemmens and Henn investigate the extent to which learning analytics has been adopted to improve teaching and learning at selected higher education institutions in South Africa. They use a framework developed by Greller and Drachsler as a means of mapping the state of LA in these selected institutions, and consider the learning analytics models currently utilised as well as the levels of LA maturity in these institutions. Their study shows that the institutions are employing various strategies based on a range of data sources to improve their understanding of the individual student, but these efforts are often hampered by data silos. This is seen as a major barrier to optimal analysis and improvement. Although there is progress in micro level analysis at most institutions, the LA maturity levels of these institutions are still relatively young. Despite this, their study shows that deployment of LA models can contribute positively to optimising student success. Lemmens and Henn stress the legal and ethical considerations of the use of student information and the need for institutional policies on this contentious issue, preferably to be developed with the involvement of students.

In their contribution, Wilson-Strydom, Strydom and Hen-Boisen make a case for the use of mixed methods and intersectional analysis in IR that is focused on student success (Chapter 13). In their case study of a South African university, they turn our attention to understanding the student through students' engagement with, and experience of, higher education. The 2015/16 "hashtag" student protests, more than ever, highlight the need for universities to know their students better. They challenge IR practitioners to move from the traditional (status quo, compliance) IR lens on students, and to focus on understanding students through their lived experiences. This requires a substantially different approach, and they submit their case study as an example for IR practitioners to consider when they are researching the student experience. Drawing on three different research projects, and using mixed methods and intersectional analysis, they show how students whose identities intersect in many ways, face different challenges that might likely affect their academic performance. This emphasises the need for an institutional approach that uses data-led evidence for nuanced, consequential and far-reaching interventions. The intent of this approach is to arrive at a holistic understanding of student success from which policy and practice can be formulated, and requires building a culture of ownership, rather than one of reporting compliance. Finally, the authors offer some principles, based on the work of Kuh (2014), to building a culture where evidence is consequential, namely: data collection should have an end use in mind; to anticipate the levels at which evidence will be used and what data type will be appropriate; to leverage quality assurance processes (beyond compliance); to connect research studies to national priorities; to link evidence to existing functions so that practice is sustained rather than episodic and so that evidence based decision-making is recognised as the start of a continuous cycle of institutional performance.

Issues of increased access, student success and quality do not only relate to undergraduate teaching and learning. In Chapter 14, Bitzer considers the question of what is meant by 
"doctorateness", and probes international and national research on doctoral education to understand the link between this and IR. Bitzer determines that IR on doctoral education in Southern Africa is still relatively immature. He establishes a number of gaps which provide critical considerations for the expanding role of IR practitioners. He argues that there is a need for IR practitioners to adopt additional roles and agendas, and provides examples of such possible future IR roles: the tracking of doctoral candidates; studies on the experiences of doctoral students; studies on candidate diversity; studies on women in doctoral research; the quality of doctoral examinations as well as the development of new, user-friendly information systems; and comparative work with other universities. This translates into a more scholarly research role for IR, including user-friendly and contextually sensitive IR data and findings. He asserts that IR has not played a coordinating role in the design and execution of projects on doctoral education but that IR could take up such a role, particularly as uncoordinated efforts result in siloed or scattered data. Another potential role is for IR to be more prominent in research projects aimed at institutional competitive advantage. By playing a more initiating and advisory part in research on doctoral education, greater efficiencies could be realised.

Although IR units in South African higher education institutions are usually not responsible for the gathering, management and reporting of research-related information (RRI), Botha and Hunter-Husselmann (Chapter 15) argue that the work related to this type of information is an important form of IR. Not all IR practitioners are organisationally located within IR units. Based on interviews with the directors of the six universities in South Africa with the highest research outputs per capita, they identify eighteen different types of research-related information and they illustrate how the custodianship for these different types of information is distributed across different units in the institutions that were investigated. Furthermore, the management of RRI has become complex and multi-faceted, and the uses of this type of information have expanded and changed significantly in recent years. RRI is used for at least four purposes, firstly, to report on research performance, secondly, to support evidencebased policy- and decision-making (including decisions on strategic directions for research), thirdly, to raise the visibility of research through various forms of science communication and fourthly, to plan, design and offer well-directed and appropriate research-support opportunities, including opportunities for funding, research collaboration, capacity building and skills development. The authors argue that the ever expanding range of uses of RRI call for a more holistic and integrated approach to the management of RRI and for a recognition that IR practitioners located in research support offices have an active and visionary role to play in decisions related to the research function of higher education institutions.

Moving to what is typically referred to as the third core function of universities, Favish (Chapter 16) investigates the current state of IR focused on engagement, the conceptual challenges related to IR focused on engagement scholarship and why there is an absence of systemic data on engaged scholarship (ES). She asserts that while there is a homogeneous set of indicators for Teaching and Learning, and for Research, there is an absence of such definitions in the field of engagement. This is not solely a South African problem. It hampers attempts to compare institutional engagement efforts within and across institutions and countries. While universities have a key role to play in promoting and enabling inclusive approaches to development through engaged research and teaching, Favish points to the 
lack of this priority in some of the key South African policy documents. She reasons that this could possibly be attributed to the lack of systemic data available on engaged scholarship. Drawing on an overview of engagement research, on the results from a survey of 12 South African higher education institutions and on a study of her own institution, she argues that it is possible to reach consensus on a national survey instrument to capture the scale of ES activities. Critical reflection on the state of ES can be enhanced by sharing the results of case studies on particular themes and by illustrating innovative approaches to the sharing of such knowledge. Finally, she throws out the gauntlet to IR practitioners: IR on higher education needs to be expanded to include a focus on engaged scholarship.

Through the inclusion of chapters on all three core academic functions, this book makes an argument in favour of a comprehensive view of IR. Such a view underscores the network of intersecting contexts and practices characterising IR in South Africa.

\section{SECTION FOUR}

In the last section of the book future directions for IR in South Africa are considered.

Prinsloo takes a critical view of the many manifestations and practices of $I R$, and in particular of the high expectations that ever more sophisticated analysis of data and information will yield ever more accurate predictions on the futures of institutions and students (Chapter 17). On the basis of a scoping review of texts that relate to the metaphor of IR as séance, he argues that while the analysis of data may resolve the conceptual problems that confront institutions and point to a way forward, it is unrealistic and possibly misleading to expect that data analysis (in its many guises such as 'data science', 'big data', 'evidence-based management', and 'learning analytics') will solve those problems or cure every institutional illness. He contests the "truthiness" and orthodoxies of optimism in the assumptions and claims surrounding evidence-based decision making in higher education. While the ever-increasing volumes, and the velocity and varieties of student digital data allow us to expand on the traditional scope of institutional research on students, it also enables us to infer relations unthinkable ten years ago. But Prinsloo warns that these abilities should not be allowed to seduce IR practitioners, institutional managers and higher education policy makers. Data has no truth. It needs to be considered and problematised in terms of power, control, domination and inequality. Data cannot speak for itself. He warns against an arrogant undercurrent in many Big Data debates. Human characteristics and agency should not be attributed to algorithms as if algorithms have the ability to act independently of their human designers. Analysts of students' digital data should not ignore the fact that students' digital footprints do not represent a total picture. Prinsloo also warns against misguided expectations of IR practitioners as data analysts or data scientists as if they resemble shamanic interlocutors, those who have access to codified knowledge and who have the skills-set to interpret the code and relay its hidden message to the audience. Finally, Prinsloo explores the concerns often expressed by IR practitioners about the lack of takeup and non-receptivity of policy-makers, and the perceived gulf between higher education researchers and policy makers. He questions whether, or to what extent, IR in all its varieties and nuances impacts on teaching and learning. On the other hand, Prinsloo maintains that our beliefs and assumptions about data and our collection and analytics processes do impact on the findings and on the lives of our students. 
In the final chapter (Chapter 18), Botha, Muller and Webber consider possible future directions for IR in South Africa. The globalised world of today's higher education requires proactive forward thinking and many old and some new challenges abound, including access for formerly underserved students, tutoring to ensure all entering students have acquired a minimum level of skills, and available staff that can meet the widening set of needs required by today's students. Economic restrictions resulting in lower government funding support to higher education may result in somewhat less autocratic requests, but lower government funding also means substantial changes in the breadth and degree of student financial aid assistance. All of these challenges prompt effective IR practitioners to have competent analytic skills as well as a deep knowledge and understanding of the inner workings of higher education.

\section{References}

Badat, S. 2016. Deciphering the South African Higher Education protests of 2015-16. Mellon Foundation Shared Experiences Blog. Available: https://mellon.org/resources/sharedexperiences-blog/ [28 June 2016].

Bawa, A.C. 2013. Righting an inverted pyramid: managing a perfect storm. Alternation, 9:25-45.

Biggs, J. 2001. The reflective institution: Assuring and enhancing the quality of teaching and learning. Higher Education, 41: 221-238. http://dx.doi. org/10.1023/A:1004181331049

Calderon, A.J. \& Webber, K.L. 2015. Institutional research, planning, and decision-support in higher education today, in K.L. Webber \& A.J Calderon (eds.). Institutional Research and Planning in Higher Education. Global Contexts and Themes. Routledge: New York. 3-15

Castells, M. Globalisation, in J. Muller, N. Cloete \& S..Badat (eds.). 2001 Challenges of Globalisation: South African Debates with Manuel Castells. Johannesburg: Pearson South Africa.

Cloete, N. \& Maasen, P. 2015. Roles of universities and the African context, in N. Cloete, P. Maasen, \& T. Baily (eds.). Knowledge production and contradictory functions in African Higher Education. Cape Town: African minds. 1-31.

Delaney, A. M. 2009. Institutional researchers' expanding roles: Policy, planning, program evaluation, assessment, and new research methodologies. New Directions for Institutional Research, 2009: 29-41. http://dx.doi.org/10.1002/ir.303
Department of Education. 2008. Report of the Ministerial Committee on Transformation and Social Cohesion and the Elimination of Discrimination in Public Higher Education Institutions. Pretoria: Government Printer.

Fincher, C. 1985. The art and science of institutional research, in M. W. Peterson \& M. Corcoran, Institutional research in transition. New Directions for Institutional Research, 46, 17-37. San Francisco: Jossey-Bass. http://dx.doi. org/10.1002/ir.37019854604

Fincher, C. 1978. Institutional research as organizational intelligence. Research in Higher Education, 8(2):189-192. http:// dx.doi.org/10.1007/BF00992119

Huisman, J. 2013. Institutional Research in Higher Education: Speaking truth to power ... and whether it would be wise to do that on your own. Keynote address at the Annual HEIR Network Meeting, 11 November 2013. Birmingham, England.

Jonathan, R. 2006. Academic freedom, institutional autonomy and public accountability in Higher Education: a framework for analysis of the 'StateSector' relationship in a democratic South Africa. Research Report. Pretoria: Council on Higher Education.

Kehm, BM. 2015. Higher Education as a field of study and research in Europe. European Journal of Education, 50(1): 60-74. http://dx.doi.org/10.1111/ ejed. 12100

Kuh, G.D. 2014. Evidence-based Decision Making: Lessons Learned. 
Leimer, C. \& Terkla, D.G. 2009. Laying the foundation: Institutional research office organization, staffing and career development. In New Directions for Institutional Research, No. 143.

Maasen, P. \& Sharma, R. 1985. What is institutional research? A Primer on institutional research in Australasia. Australasian Association for Institutional Research.

Reichard, D.J. 2012. The history of institutional research, in R.D. Howard, G.W. McLaughlin \& W.E. Knight (eds.). The Handbook of Institutional Research (pp. 3-21). San Francisco, CA: JosseyBass. 3-21.

Republic of South Africa (RSA). 1996. Constitution of the Republic of South Africa Act. Government Gazette. December.

Republic of South Africa (RSA). Department of Education. 1997a. Education White Paper 3. A programme for the transformation of higher education. Government Gazette General Notice 1196 of 1997. Pretoria: Government Printer.

Republic of South Africa (RSA). Department of Education. 1997b. Higher Education Act. Government Gazette. November.

Republic of South Africa (RSA). Department of Education. 2001. National Plan for Higher Education. Pretoria: Government Printer.

Republic of South Africa (RSA). Department of Higher Education and Training. 2014. The White Paper for Post-School Education and Training. Pretoria: Government Printer.

Republic of South Africa (RSA). The Presidency. National Planning Commission. 2012. National Development Plan 2030: Our future make it work. Pretoria: Government Printer.

Saupe, J. L. 1990. The functions of institutional research (2nd ed.). Tallahassee, FL: Association for Institutional Research.

Singh, M. 2001. Re-Inserting the 'Public Good' into Higher Education Transformation. Kagisano 1:8-19.

Serban, A. 2002. Knowledge Management: The Fifth Face of Institutional Research.
New Directions for Institutional Research 113:105-111. http://dx.doi.org/10.1002/ ir.40

Tabensky, P. \& Matthews, S. (eds.) 2015. Being at home: race, institutional culture and transformation at South African Higher Education Institutions, Durban: University of KwaZulu-Natal Press.

Teichler, U. 2000. Higher education research and its institutional basis in S. Schwarz \& U. Teichler (eds.). The institutional basis of higher educational research.. Dordrecht, Netherlands: Klewer Academic Publishers. 13-24.

Terenzini, P. T. 1993. On the nature of institutional research and the knowledge and skills it requires. Research in Higher Education, 34, 1-10. http://dx.doi. org/10.1007/BF00991859

Terenzini, P. T. 2013. "On the Nature of Institutional Research" Revisited: Plus c, a Change? Research in Higher Education 54 (2):137-148. http://dx.doi. org/10.1007/s11162-012-9274-3

Universities South Africa. 2015. Reflections on Higher Education: briefing paper prepared for the Second National Higher Education Transformation Summit. Pretoria: USAf.

Volkwein, J.F. (ed.). 1999. What is institutional research all About? A critical and comprehensive assessment of the profession. New Directions for Institutional Research, 104:9-19.

Volkwein, J. F. 1999. The four faces of institutional research, in J.F. Volkwein (ed.). IR: What is it all about? New Directions for Institutional Research, 104:9-19. http://dx.doi.org/10.1002/ ir. 10401

Volkwein, J.F. 2008. The Foundations and Evolution of Institutional Research. New Directions for Institutional Research, 141:5-20. http://dx.doi.org/10.1002/ he. 289

Webber, K. \& Calderon, A. (eds.) 2015. Institutional research and higher education planning: Global themes and contexts. New York: Routledge Press.

Whitchurch, C. 2013. Reconstructing identities in higher education. The rise of third space professionals. Abingdon: Routledge. 